\title{
The Clinical Efficacy of Enzalutamide in Metastatic Prostate Cancer: Prospective Single-center Study
}

\author{
GIUSEPPE CICERO $^{1}$, ROSSELLA DE LUCA ${ }^{1}$, PATRIZIA DORANGRICCHIA ${ }^{1}$ and FRANCESCO DIELI ${ }^{2}$ \\ ${ }^{1}$ Department of Surgical, Oncological and Oral Sciences, Section of Medical Oncology, \\ ${ }^{2}$ Central Laboratory of Advances Diagnosis and Biomedical Research (CLADIBIOR), \\ University of Palermo, Palermo, Italy
}

\begin{abstract}
Background/Aim: To evaluate the effectiveness of enzalutamide in Italian patients with hormone-refractory metastatic castration-resistant prostate cancer, progressing after chemotherapy with docetaxel plus prednisone. Patients and Methods: A total of 60 patients were enrolled. Reduction in serum prostate-specific antigen (PSA) was assessed as the primary endpoint, while reduction in pain, safety, progression-free survival and overall survival represented secondary endpoints. Results: Enzalutamide was well tolerated, with a manageable toxicity profile and a modest objective response rate. A considerable difference in serum levels of PSA before and after treatment was observed. A significant correlation between PSA response and overall survival was also noted. The regression analysis revealed PSA level to be predictive of overall survival. Conclusion: Enzalutamide was shown to be an effective and welltolerated therapeutic option in patients with metastatic castration-resistant prostate cancer progressing after docetaxel plus prednisone treatment.
\end{abstract}

In most Western countries, prostate cancer is the most frequently diagnosed cancer in men (1). Prevalence increases with age and, according to the data published in literature, it is estimated that $40 \%$ of men older than 50 years old are affected by the disease, while only $10 \%$ go on to develop clinical symptoms $(2,3)$. In the treatment of metastatic castrationrecurrent prostate cancer (mCRPC), over the past 15 years several drugs have been evaluated $(4,5)$ and they have significantly improved the median overall survival (OS) (6-10). Although recent studies show that androgenic activity continues

Correspondence to: Professor Giuseppe Cicero, MD, Ph.D., Department of Surgical, Oncological and Oral Sciences, University of Palermo, Via del Vespro, n. 129, 90127 Palermo, Italy. Tel: +39 0916554531, Fax: +39 0916552549, e-mail: giuseppe.cicero@unipa.it

Key Words: Adenocarcinoma, prostate cancer, enzalutamide, prednisone, drug resistant, docetaxel, chemotherapy. to play a role in promoting $\mathrm{mCRPC}$, the use of secondgeneration hormonal agents, such as abiraterone and enzalutamide, has been indicated, in patients whose disease progresses after hormone therapy $(11,12)$ They have been proven effective compared to placebo both in chemo-naïve patients and in those with progression after first-line chemotherapy with docetaxel $(13,14)$. Enzalutamide is a 'new' anti-androgen with greater affinity for androgen receptors which competitively inhibits the binding of androgens to androgen receptors, inhibits nuclear translocation of activated receptors and inhibits binding of activated androgen receptor with DNA, even in the case of overexpression of the androgen receptors and in prostate cancer cells resistant to anti-androgens (15).

In phase I and II clinical trials where patients were enrolled with diagnosis of CRPC (even if pretreated with chemotherapy), conducted by the Prostate Cancer Clinical Trials Consortium, enzalutamide had significant antitumor activity regardless of previous chemotherapeutic treatments (16-18). Considering these results, other studies have been conducted on the effectiveness of enzalutamide in prostate cancer, including the AFFIRM study (A Study Evaluating the efficacy and Safety of the Investigational Drug MDV3100), an international, phase III, randomized, double-blind, placebo-controlled study of enzalutamide in patients with prostate cancer who had previously been treated with one or two chemotherapy regimens, at least one of which containing docetaxel (18). The authors aimed to evaluate whether enzalutamide would prolong life in men with CRPC progressing after chemotherapy. An analysis of the study results showed that in the group treated with enzalutamide, the median overall survival (OS) was 18.4 months compared to 13.6 months in the control group. In addition, in relation to secondary endpoints (radiographic progression-free survival, median time to progression of prostate-specific antigen (PSA), median time to onset of first skeletal event), patients who received enzalutamide had statistically significantly better results compared to the control group. The tolerability profile of enzalutamide was well accepted, with few adverse events, mostly mild to moderate (18). 
Considering the validity of these clinical trials, the United States Food and Drug Administration and the European Medicines Agency approved the administration of enzalutamide as a standard recommended therapy for the treatment of mCRPC progressing after docetaxel plus prednisone (19). In accordance with studies in literature (20, 21 ), the main purpose of this prospective study was to evaluate under our clinical reality the safety and efficacy of enzalutamide (Xtandi ${ }^{\circledR}$ ) in patients with mCRPC progressing after docetaxel plus prednisone. In particular, analysis of the reduction in serum prostate-specific antigen (PSA) was assessed as the primary endpoint for evaluating the effectiveness of treatment with enzalutamide. Secondary end-points were pain response, tolerability, OS and progression-free survival (PFS). Our specific objectives were to: (i) Evaluate the effectiveness of the treatment in terms of reduction in serum levels of PSA. In accordance with clinical trials $(31,32)$, it was assumed significant differences in serum level of PSA would be found between the time from diagnosis (pre-treatment) and the end of treatment (post treatment). (ii) Investigate any significant relationships between PSA response rate to second-line enzalutamidebased treatment $\left(\mathrm{Xtandi}^{\circledR}\right)$ and OS. (iii) Evaluate whether PSA response to treatment may serve as a predictor of OS. It was assumed a link between PSA response rate and significantly higher OS would exist. (iv) Analyze the intensity of the link between variability of PSA response and pain relief.

\section{Patients and Methods}

In this prospective study, we enrolled a total of 60 consecutive patients diagnosed with mCRPC between January 2014 and June 2016 at the Medical Oncology Unit of the University of Palermo. As in our pervious study (22), all patients enrolled in this study had to meet the following inclusion criteria: (i) histologically or cytologically confirmed diagnosis of metastatic prostate adenocarcinoma (mCRPC) in progression after prednisone plus docetaxel failure according to the Response Evaluation Criteria in Solid Tumors (RECIST v. 1.1) (23), (ii) performance status of 0 to 2 according to the Eastern Cooperative Oncology Group (ECOG), (iii) clinical or radiological evidence of metastatic disease (number of lesions $\geq 1$ ) and with an adequate liver, renal and blood functionality. Patients were excluded if they were hypersensitive to enzalutamide and its excipients or other formulation components, had a diagnosis of other malignancies (with the exception of properly treated basal cell carcinoma of the skin) or serious comorbidities not adequately controlled by other ongoing therapies (e.g. liver disease, diabetes, infection, heart disease, etc.).

Evaluation of response and toxicity. Before the start of each cycle of treatment, we assessed the response rate evaluation in terms of reduction of both PSA and measurable disease (4 weeks after the end of treatment), then we evaluated it every 3 months until disease progression. Whenever there was a rise in PSA, patients underwent radiological examinations (such as chest and abdomen computed tomographic scan) every 6 months and always before administration of therapy, while bone scan was performed before starting the treatment, then every 6 or 12 months according to the physician's choice and patient characteristics. If patients did not have measurable disease, we considered as response to treatment a sustained reduction in serum PSA level by $\geq 50 \%$ from baseline.

Modality of administration. Patients received enzalutamide (Xtandi ${ }^{\circledR}$ ) as $40 \mathrm{mg}$ tablets to be taken as a single dose $160 \mathrm{mg}$ daily (four tablets of $40 \mathrm{mg}$ ) on an empty stomach for 4 weeks until disease progression, death, development of severe complications or unacceptable adverse events.

Statistical analysis. Normality of the distribution was checked using univariate indices of Kurtosis and asymmetry with an acceptance threshold equal to 1 . No variable violated normality indices.

In order to provide a sociodemographic representation of the study group patients and explore how to distribute the examined variables, descriptive statistical analyses were carried out. Inferential statistical analyses were also performed to detect any significant relationships among the considered variables.

The disease control rate (DCR) was defined as the percentage of patients with an objective response or stable disease (SD) lasting $>6$ months. PFS and OS were calculated from the date of beginning treatment until the date of disease progression or death from any cause for PFS, and until the date of last follow-up, death or final follow-up day of evaluation for OS. The cut-off date was 30 June 2016. PFS and OS curves were estimated by using the KaplanMeier method. In order to evaluate PSA response (both in terms of subjective and objective response), the analysis of the average serum PSA level before and after the end of treatment with enzalutamide was carried out using the paired-sample $t$-test.

In order to analyze the correlation between PSA response and OS, or the time of diagnosis or treatment until death, the BravaisPearson linear correlation index $(\mathrm{r})$, with a $95 \%$ confidence interval (CI) was used. This index was also used to measure the intensity of the correlation between the variability of PSA response and the reduction of pain. In addition, the association between PSA as the independent variable and OS as the dependent variable was determined. Data were represented by scatter plot and regression line. Given the sample size, parametric statistics were used and a threshold of $p=0.05$ to evaluate the significance of the obtained results was considered. Data processing were performed using the SPSS Statistical Package for Social Science version 19.0 (IBM Corp., Armonk, NY, USA).

\section{Results}

Treatment response and follow-up. Demographic, clinical and pathological features of 60 patients with $\mathrm{mCRPC}$ are reported in Table I. At diagnosis, patients were aged between 48 and 85 years, with an average age of 68 years.

Nearly all patients were able to undergo a median of 12.0 cycles (range $=0.2-17.2$ ).

The response rate of total PSA after four cycles was $75 \%$ (45 out of 60 patients). After a median follow-up of 14.4 months (range $=8-26$ months), no patient had a complete response (CR) to treatment, 24 patients $(40 \%)$ had a partial response (PR), 20 patients (33\%) had SD, while $16(27 \%)$ 
Table I. Baseline demographic and clinical characteristics $(n=60)$.

\begin{tabular}{lc}
\hline Characteristic & Value \\
\hline Patients & $\mathrm{n}=60$ \\
Mean age (range), years & $68(48-85)$ \\
ECOG performance status, $\mathrm{n}$ & \\
0 & 3 \\
1 & 55 \\
2 & 2 \\
PPI 2 or AS 10, $\mathrm{n}$ & 60 \\
Hormonal manipulations, $\mathrm{n}$ & \\
I & 8 \\
II & 32 \\
III & 20 \\
Previously treated with DP, $\mathrm{n}$ & 60 \\
Median PSA level (range), ng/ml & $11.2-2057)$ \\
Gleason score, $\mathrm{n}$ & \\
7 & 38 \\
$8-10$ & 20 \\
$\quad$ Not available & 2 \\
Disease extent, $\mathrm{n}$ & \\
Bone and visceral metastases & 38 \\
Visceral disease & 2 \\
Lymph nodes & 20 \\
\hline
\end{tabular}

ECOG: Eastern Cooperative Oncology Group; PPI: present pain intensity; AS: analgesic score; DP: docetaxel plus prednisone; PSA: prostate-specific antigen.

had experienced disease progression (PD). Treatment with enzalutamide was well tolerated and resulted in a good level of disease control (CR + PR + SD: $50 \%)$.

PSA reduction. In our study of patients treated with enzalutamide, we found an impact on serum PSA level. In particular, the average reduction was $42.3 \%(95 \% \mathrm{CI}=39.61$ $44.98 \%$ ), consistent with previously published data, moreover associated with improved survival (Figure 1).

In order to evaluate PSA response, the analysis of the average serum PSA levels before and after the end of treatment with enzalutamide was carried out by the pairedsample $t$-test which showed the serum PSA level to be significantly lower after treatment with enzalutamide $(t=14.95, p<0.01)$ (Table II).

Overall survival analysis. Among the 60 patients enrolled in this study, updated interim analysis of survival (until last follow-up in 30 June 2016) showed a median OS of 18 months (Figure 2).

The Bravais-Pearson index showed there to be a positive correlation between the response rate of PSA with $40 \mathrm{mg}$ enzalutamide (four doses per day, $160 \mathrm{mg}$ ) and OS, with a value of 0.50 . Furthermore, regression analysis between PSA response rate to the second line of treatment with $40 \mathrm{mg}$
Table II. The average prostate-specific antigen (PSA) pre- and posttreatment with enzalutamide $(n=60)$.

\begin{tabular}{|c|c|c|c|c|}
\hline \multirow[b]{2}{*}{ Timepoint } & \multicolumn{2}{|c|}{ PSA, ng/ml } & \multicolumn{2}{|c|}{ Paired-sample test } \\
\hline & Mean & SD & $t$ & $p$-Value \\
\hline Pre-treatment & 31.14 & 7.98 & 14.95 & 0.007 \\
\hline Post-treatment & 18 & 6.17 & & \\
\hline
\end{tabular}

enzalutamide (four doses per day, $160 \mathrm{mg}$ ) and OS gave a value of $\mathrm{R}^{2}$ of 0.42 with a slope of $1.48(p=0.0021)$ (Figure 1$)$.

Analysis of PFS time. In our cohort, the median duration of response was 5.4 months (range $=3.8-8.4$ months), while the median time to progression was 8 months $(95 \% \mathrm{CI}=7.878$ 8.122) (Figure 3).

Tolerability. In the group of patients treated with enzalutamide, side-effects were evaluated after each course of therapy and reported in line with CTCAE version 4.0. The treatment-related toxicity was well tolerated, with a manageable toxicity profile and a modest objective response rate.

Pain response. Pain reduction as assessed by Visual Analogue Scale (VAS) showed a pain was reduced in $47 \%$ of patients. In addition, improvement of the quality of life was identified with a reduction of pain symptoms in $58 \%$ of patients with a VAS score of $<22$ points and a reduced use of analgesics in 54\% of patients. Bravais-Pearson correlation was also used to analyze the intensity of the association between PSA response and the reduction of pain. The results revealed a significant negative correlation between PSA response and reduction of pain of -0.58 . The higher the PSA response to treatment, the better was the response in terms of pain relief.

\section{Discussion}

Nowadays, therapeutic strategies in prostate cancer still call for different goals depending on anatomical extension, aggressiveness of the disease and presence of life-threatening comorbidities $(24,25)$. Whilst the goal of treatment for patients affected by organ-confined disease is remission, in patients with metastatic disease, palliation remains the most practically achievable goal, especially in symptomatic patients, who are currently offered various options of hormone therapy and chemotherapy, significantly improving their quality of life, together with the latest forms of radioiodine therapy (alpha channels) and bone-targeted therapies (26). 


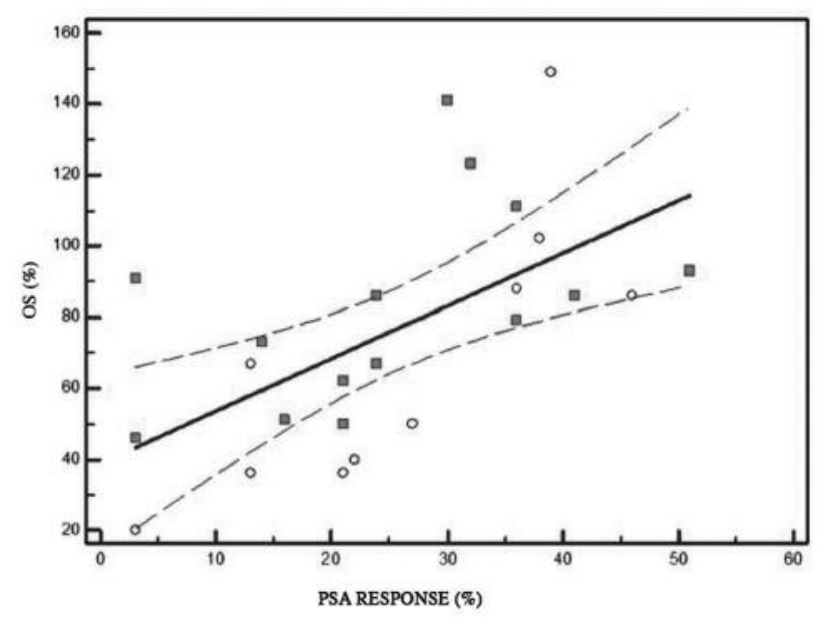

Figure 1. Regression analysis between prostate-specific antigen (PSA) response and overall survival (OS) of patients after second-line treatment $(n=60)$.

An important category of hormonal drugs is represented by antibodies to androgen receptors expressed by cancer cells. Recently, two new drugs have been introduced in hormonal therapy, abiraterone acetate and enzalutamide (27). Although of relatively few clinical records, our study demonstrated the efficacy and safety of enzalutamide $\left(\mathrm{Xtandi}^{\circledR}\right)$ in patients with mCRPC previously treated with a chemotherapy regimen containing docetaxel plus prednisone, complying with clinical trials reported in literature (AFFIRM) (18).

In our group of patients, treatment with enzalutamide was well tolerated, while a modest objective response rate and a good reduction in PSA levels was obtained. In fact, a significant difference in the serum level of PSA before and after treatment was noted. Compared to the chemotherapeutic treatment, a better response in terms of reduction of serum PSA level after administration of enzalutamide was gained. Moreover, considering the better the response of PSA to treatment the higher the overall survival rate, correlation analysis showed that the PSA response rate significantly affects survival. This finding corresponds with studies reported in the literature where the analysis of serum PSA level represented the surrogate endpoint for the the effectiveness of the treatment. In addition, according to the fourth objective of the present study, we analyzed the correlation between PSA response and reduction of pain, finding that pain was more present whenever a better response of PSA to treatment occurred. Given the strong association between the two variables, we wanted to understand if the PSA response could be a predictive factor for OS using the linear regression analysis. The positive correlation between PSA response and OS $(\beta=0.377, p<0.01)$, obtained by linear regression analysis

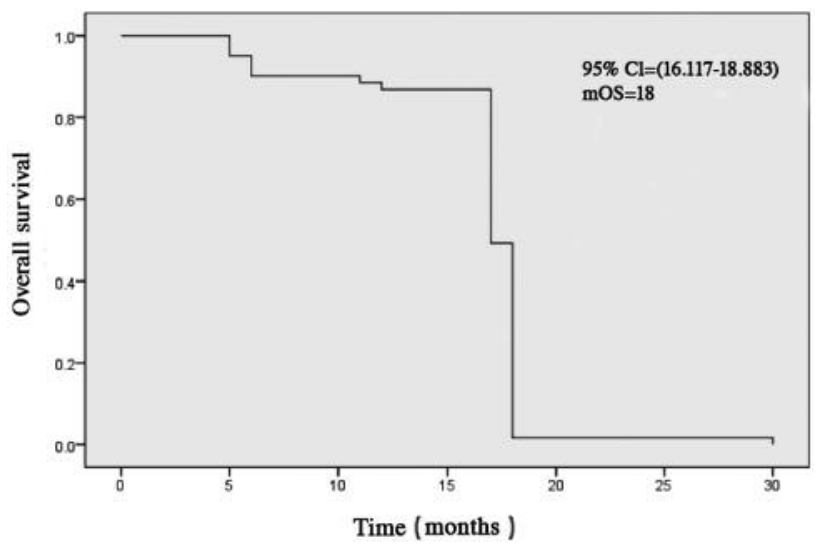

Figure 2. Kaplan-Meier plot of overall survival (interim analysis) $(N=60)$. mOS: Median overall survival.

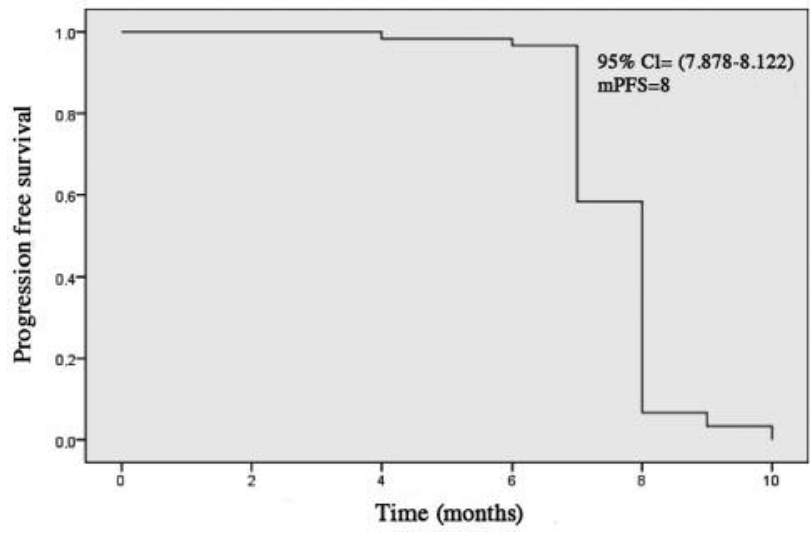

Figure 3. Kaplan-Meier plot of progression-free survival (interim analysis) $(N=60)$. mPFS: Median progression-free survival.

revealed that PSA response is an important predictor of OS. The slope value suggests that for every month of PFS, OS increased by about 1.5 months following treatment. The median PFS and OS values of 8.3 and 18.2 months, respectively, appear to be in conformity with the values reported in the AFFIRM study (18).

Our results are in line with those reported in the literature, but there are aspects that undoubtedly are highlighted in comparison with the larger studies. These include (besides the small size of the sample), the criteria used for the response evaluation and the difference in the definition of MCRPC in our clinical practice (three consecutive increases of serum PSA 2 weeks apart, resulting in two increments above the lowest point of 50\%) compared to the last criteria of the PSA working group (a sequence of increase of the PSA value to a 
minimum of one week to week interval with a PSA level greater than $2 \mathrm{ng} / \mathrm{ml}$ as a starting value). Nowadays the physician's main problem is to identify the best sequence of drugs for mCRPC. The analysis of the largest available studies (28-30) showed that the best sequence able to achieve better results in terms of OS would be probably docetaxel> cabazitaxel> abiraterone or enzalutamide. Thus, use of enzalutamide, as suggested by our study of mCRPC, could be considered as a valid treatment of mCRPC.

\section{Conclusion}

The results obtained from this prospective study, also referring to the outcomes of clinical trials reported in the literature, revealed that enzalutamide is a well-tolerated and effective treatment of patients affected by mCRPC. The drug showed an improved tolerability profile, gave significant pain relief and increased the survival rate. Therefore, enzalutamide (Xtandi ${ }^{\circledR}$ ) administered daily at a dose of $160 \mathrm{mg}$ orally is an excellent treatment for most patients with mCRPC progressing after treatment with docetaxel plus prednisone.

\section{Conflicts of Interest}

The Authors have nothing to disclose.

\section{References}

1 Siegel RL, Miller KD and Jemal A: Cancer statistics. CA Cancer J Clin 65: 5-29, 2015.

2 Documento AIOM-AIRTUM. I numeri del cancro in Italia, 2015. www.aiom.it

3 Bray F, Lortet-Tieulent J, Ferlay J, Forman D and Auvinen A. Prostate cancer incidence and mortality trends in 37 European countries: an overview. Eur J Cancer 46: 3040-3052, 2010.

4 Ahmadi $\mathrm{H}$ and Daneshmad S: Androgen deprivation therapy: evidence-based management of side effect. BJU International 111: 543-548, 2013.

5 Tucci M, Scagliotti GV and Vignani F: Metastatic Castration Resistant Prostate Cancer: time for innovation. Future Oncol 11: 91-106, 2015.

6 Oudard S: TROPIC: Phase III trial of cabazitaxel for the treatment of metastatic castration-resistant prostate cancer. Future Oncol 7: 497-506, 2011.

7 Chi K, Scher H, Molina A, Logothetis C, Jones R and Staffurth $\mathrm{J}$ : Exploratory analysis of survival benefit and prior docetaxel (D) treatment in COU-AA-301, a phase III study of arbiraterone acetate (AA) plus prednisone $(\mathrm{P})$ in metastatic castration-resistant prostate cancer (mCRP). J Clin Oncol 30: suppl 5; abstr 15, 2012.

8 Beer TM, Armstrong AJ, Rathkopf DE, Loriot Y, Sternberg CN, Higano CS, Iversen P, Bhattacharya S, Carles J, Chowdhury S, Davis ID, de Bono JS, Evans CP, Fizazi K, Joshua AM, Kim CS, Kimura G, Mainwaring P, Mansbach H, Miller K, Noonberg SB, Perabo F, De Phung BS, Saad F, Howard I. Scher HI, Taplin ME, Venner PM, and Tombal B, for the PREVAIL Investigators:
Enzalutamide in Metastatic Prostate Cancer before Chemotherapy. N Engl J Med 371: 424-433, 2014.

9 Tannock IF, de Wit R, Berry WR, Horti J, Pluzanska A, Chi KN, Oudard S, Thèodore C, James ND, Turesson I, Rosenthal MA, Eisenberg MA: Docetaxel plus prednisone or mitoxantrone plus prednisone for advanced prostate cancer. N Eng J Med 351: 1502-1512, 2004.

10 Caffo O, Sava T, Comploj E, Fariello A, Zustovich F, Segati R, Sacco C, Veccia A and Galligioni E: Impact of docetaxel-based chemotherapy on quality of life of patients with castrationresistant prostate cancer: results from a prospective phase II randomized trial. BJU Int 108: 1825-1832, 2011.

11 Buttigliero C, Tucci M, Bertaglia V, Vignani F, Bironzo P, Di Maio M, Scagliotti GV: Understanding and overcoming the mechanisms of primary and acquired resistance to abiraterone and enzalutamide in castration resistant prostate cancer. Cancer Treat Rev 41: 884-892, 2015.

12 Parker C, Gillessen S, Heidenreich A and Horwich A: Cancer of the prostate: ESMO Clinical practice guidelines for diagnosis, treatment and follow-up. Ann Oncol 26: 69-77, 2015.

13 Rodriguez-Vida A, Galazi M, Rudman S, Chowdhury S and Sternberg CN: Enzalutamide for the treatment of metastatic castration-resistant prostate cancer. Drug Design, Development and Therapy 9: 3325-3339, 2015.

14 Ryan CJ, Smith MR, de Bono JS, Molina A, Logothetis CJ, de Souza P, Fizazi K, Mainwaring P, Piulats JM, Siobhan Ng, Carles J, Mulders FAP, Basch E, Small EJ, Saad F, Schrijvers D, Van Poppel H, Mukherjee SD, Suttmann H, Gerritsen WR, Flaig TW, George DJ, Evan Y, Efstathiou E, Pantuck A, Winquist E, Higano CS, Taplin ME, Park Y, Kheoh T, Griffin T, Scher HI and Rathkopf DE: Abiraterone in metaastatic prostate cancer without previous chemotherapy. N Engl J Med 368: 138-148, 2013.

15 Schrader AJ, Boegemann M, Ohlmann CH, Schnoeller TJ, Krabbe LM, Hajili T, Jentzmik F, Stoeckle M, Schrader M, Herrmann E and Cronauer MV: Enzalutamide in castrationresistant prostate cancer patients progressing after docetaxel and abiraterone. Eur Urol 65: 30-36, 2013.

16 Cella D, Ivanescu C, holmstrom S, Bui CN, Spalding J, Fizazi $\mathrm{K}$ : Impact of Enzalutamide on quality of life in men with metastatic castration-resistant prostate cancer after chemotherapy: additional analyses from the AFFIRM randomized clinical trial. Ann Oncol 26: 179-185, 2015.

17 Scher HI, Beer TM, Higano CS, Anand A, Taplin ME, Efstathiou E, Rathkopf D, Shelkey J, Yu EY, Alumkal J, Hung D, Hirmand M, Seely L, Morris MJ, Danila DC, Humm J, Larson S, Fleisher $\mathrm{M}$ and Sawyers CL: Prostate Cancer Foundation/Department of Defense Prostate Cancer Clinical Trials Consortium. Antitumour activity of MDV3100 in castration-resistant prostate cancer: a phase 1-2 study. Lancet 24: 1437-1446, 2010.

18 Scher HI, Fizazi KF, red Saad, Taplin EM, Sternberg CN, Miller K, de Wit R, Peter Mulders P, Kim N. Chik KN, Shore ND, Andrew J. Armstrong AJ, Flaig TW, Fléchon A, Mainwaring P, Fleming M, Hainsworth JD, Hirmand M, Selby B, Seely L and de Bono JS: Increased survival with Enzalutamide in prostate cancer after chemotherapy. N Engl J Med 367: 1187-1197, 2012.

19 US Department of Health and Human Services, Food and Drugs Administration Guidance for industry: patient-reported outcome meseaure-Use in medical product development to support labeling claims: Draft guidance released for commen. Feb 2006 htpp:// www.fda.gov./CDER7GUIDANCE/5460dft.pdf. 
20 Crawford ED, Higano CS, Shone ND, Hussain M and Petrylak DP: Treating patients with metastatic castration resistant prostate cancer: a comprehensive review of available therapies. J Urolog 194: 1537-1547, 2015.

21 Loblaw DA, Walker-Dilks C and Winquist E: Systemic therapy in men with metastatic castration-resistant prostate cancer: a systematic review. Clinical Oncology 25: 406-430, 2013.

22 Cicero G, De Luca R, Dorangricchia P, Galvano A, Lo Re G, Serretta V, Dispensa N and Dieli F: Cabazitaxel in Metastatic Castration-resistant prostate cancer patients progressing after docetaxel: a prospective single-center study. Oncology 92: 94$100,2016$.

23 Eisenhauer EA, Therasse P, Bogaerts J, Schwartz LH, Sargent D, Ford R, Dancey J, Arbuck S, Gwyther S, Mooney M, Rubinstein L, Shankar L, Dodd L, Kaplan R, Lacombe D and Verweij J: New response evaluation criteria in solid tumours: revised RECIST guideline (version 1.1). Eur J Cancer 45(2): 228-247, 2009.

24 Di Lorenzo G, Buonerba C, Autorino R, De Placido S and Sternberg CN: Castration-resistant prostate cancer. Drugs 70(8): 983-1000, 2012.

25 Omlin A. Pezaro C and Sommer SG: Sequential use of novel therapeutics in advanced prostate cancer following docetaxel chemotherapy. Therapeutic Advances in Urology 6(1): 3-14, 2014.

26 Nussbaum N, George DJ, Abernethy AP, Dolan CM, Oestreicher $\mathrm{N}$, Flanders S and Dorff TB: Patient experience in the treatment of metastatic castration-resistant prostate cancer: state of the science. Prostate Cancer Prostate Dis 19: 111-121, 2016.

27 Kirby M, Hirst C and Crawford ED: Characterising the castration-resistant prostate cancer population: a systematic review. Int J Clin Pract 65: 1180-1192, 2011.
28 Tran C, Ouk S, Clegg NJ, Chen Y, Watson PA, Arora V, Wongvipat J, Smith-Jones PM, Yoo D, Kwon A, Wasielewska T, Welsbie D, Chen CD, Higano CS, Beer TM, Hung DT, Scher HI, Jung ME and Sawyers CL: Development of a second-generation anti-androgen for treatment of advanced prostate cancer. Science 324: 787-790, 2009.

29 Scher HI, Halabi S, Tannock I, Morris M, Sternberg CN, Carducci MA, Eisenberger MA, Higano C, Bubley GJ, Dreicer R, Petrylak D, Kantoff P, Basch E, Kelly WK, Figg WD, Small EJ, Beer TM, Wilding G, Martin A and Hussain M: Prostate Cancer Clinical Trials Working Group: Design and point of clinical trials for patients with progressive prostate cancer and castrate levels of testosterone: recommendations of the Prostate Cancer Clinical Trials Working Group. J Clin Oncol 26: 11481159, 2008.

30 Rodriguez-Vida A, Bianchini D, Van Hemelrijck M, Hughes S, Malik Z, Powles T, Bahl A, Rudman S, Payne H, de Bono J and Chowdhury $\mathrm{S}$ : Is there an anti-androgen withdrawal syndrome with enzalutamide? BJU Int 115(3): 373-380, 2015.
Received January 17, 2017

Revised February 24, 2017

Accepted February 28, 2017 